\title{
Sociocultural aspects of international students' speech behavior: mixed method in language teaching
}

\author{
Alla Sokolova ${ }^{1}$, Dzhamilya Khuchbarova ${ }^{2}$, and Alexandra Radyuk ${ }^{3, *}$ \\ ${ }^{1}$ National Research Moscow State University of Civil Engineering, 26, Yaroslavskoye shosse, \\ 129337, Moscow, Russia \\ ${ }^{2}$ Academy of Strategic Rocket Troops after Peter the Great, 8, Karbysheva str., 143900, Moscow \\ Region, Balashikha, Russia \\ ${ }^{3}$ RUDN University, 6, Miklukho-Maklaya str., 117198, Moscow, Russia
}

\begin{abstract}
In the present research, the authors have studied direct and indirect cross-cultural contact as well as motivated behavior and language attitude in a study-abroad context on the territory of the Russian Federation. For the research purposes, the mixed method combining quantitative and qualitative research methodologies was applied in order to demonstrate contact, behavioral and motivational variables throughout one academic year of the foundation programme. The authors attempted to identify the main factors affecting the language learning motivation of international students studying in Russian international programs, to define the type and frequency of the contact with the maximum impact on students' perception of the language acquisition. The results of encounter experiences were registered at three discrete points throughout the academic year. The detailed analysis showed that written and media use contacts had become more frequent throughout the year while the direct spoken contacts had exhibited the opposite tendency. The authors attempted to give some recommendations that would encourage contact opportunities and reduce inter-group anxiety among foreign students. The implemented analysis of the research results has demonstrated that selfconfidence of international students had suffered immensely as the result of the negative encounter experiences. This type of experiences could be fully eliminated or reduced to a minimum if the hosts were aware of the expectation, attitudes, feelings, and possible forms of the international students' behavior. The study proved out the necessity of potential students to prepare for the study abroad programs before their arrival to the host country. They are supposed to develop communication skills and strategies as well as their linguistic ability. A necessary precondition for students upon their arrival is the provision of institutional support, which allows them to get used to new cultural and social environment and to bond with native speakers.
\end{abstract}

\footnotetext{
*Corresponding author: radyuk-av@rudn.ru
} 


\section{Introduction}

Learning Russian as the Second Language involves studying not only the language itself but also cultural aspects. Learning another language could serve as a portal to the historical perspectives, literatures, cultures and experiences of humanity accumulated over centuries. This is especially true in study-abroad contexts when learners are engaged in immediate interaction with the representatives of other cultures, and such intercultural encounters have great impact on student's identification with a particular cultural and ethnical group. This leads to formation of the value of student's own cultural awareness in relation to those belonging to other cultural groups [1]. Cross-cultural communication affects disposition of learners of Russian as the Second Language towards acquiring the language skills and motivating their behavior.

The aim of this intercultural experience for international learners studying abroad is to communicate and interact with the host country members and in this manner acquire more profound understanding of their culture. Academic mobility and other study abroad student exchange programme are often organized and sponsored in the belief that students would be involved in contact situations, and their cross-cultural sensitivity and understanding the culture of a Target Language country is to be enhanced. At the same time, second language competence will be immensely improved $[2,3]$. Studying in technical universities in the Russian language could be challenging for international students as no programs are realized in English at the moment in the given university, and even Russian-speaking students usually struggle with certain disciplines, such as theoretical mechanics, strength of materials, or perspective geometry.

\section{Materials and methods}

\subsection{Participants}

The present research was implemented with international students taking part in a foundation programme on the university campus in the Russian Federation. The program's aim is to prepare students for entering the engineering programs in the Russian university within one academic year. In the technical university, the students received thirty hours of Russian language instruction per week during nine months or one academic year. The language component provided tuition in academic skills and aimed to develop learners' ability to understand and produce written and spoken academic texts. By the year end, the students sat an exam in both Russian language and the appropriate discipline of further studies (mostly engineering) and supposed to reach B1 level of Russian language command according to standards of the European classification. The foundation programme is a common example of preparatory courses for university entry offered in the Russian Federation, as far as curriculum is concerned, unfortunately the most of teaching is done online nowadays due to the quarantine restrictions.

Altogether, more than 1000 foreign students from 87 countries are presently enrolled in the University. They represent different cultures, traditions, customs and language. Also, there was established Interclub, the main international community in the system of crosscultural communication and formation of the united educational space. The mission of this vocational organization is understanding creativity and beauty of all nationalities as the club is open for representatives of all nations sharing the goals and mission of the organization without any limitation. 
In the survey, 60 international students from a great variety of ethnic backgrounds took part, with the majority being Vietnamese $(65 \%)$. Seven percent of the students were French speakers of Tunisian and Moroccan origin, and the others were representing such countries as Nigeria, India, Pakistan, Congo, Uganda and China. The level competence of the students at the beginning of the course is assessed as elementary. Forty-two per cent of the partaking students were male and fifty-eight per cent female, whereas their age ranging between 23 and 29. The interview participants were chosen from a pool of volunteers so that they could represent different nationalities and ethnical background. The interviews were conducted a year after the quantitative data had been collected and systematized which means that the interviewees did not fill in the questionnaires throughout the preceding stages of the research. We didn't predetermine the number of interview participants and kept collecting data until we believed we had reached saturation. Thus, we've interviewed 10 students and two course lecturers, both native speakers of the Russian language. By the interview date, the teachers had been working in this foundation program for more than 5 years, so they were considered quite experienced and professional specialists.

\subsection{Instruments and procedures}

The questionnaire containing 50 items was aimed to evaluate four aspects of contact such as direct spoken and written contact, media contact and the importance of contact perceived. Also the questionnaire indirectly assessed motivated behavior, language learning attitude as well as language learning goals. The items of the questionnaire were based on the study of the scientists Csizér and Kormos (2009) investigating the role of intercultural encounter in motivation and insignificantly adapted to suit the context of study-abroad programmes. Correspondingly, the questions on motivational parameters were adapted from the instrument by Kormos, Kiddle and Csizér (2011). The questionnaire was written in the Russian language.

The principal variable categories were defined as the following:

- 5 items for direct spoken contact (frequency of direct spoken encounters with native and non-native speakers of Russian);

- 5 items for direct written contact (frequency of conventional mail, e-mail letters, the use of messenger, social networks and chatting on the Internet);

- 5 items for media contact the Target language by watching TV programs, reading newspapers, magazines, the use of Russian-language websites;

- 5 items for perceived importance of contact as an indispensable tool for enriching their language, getting to know the language culture, and reducing anxiety level;

- 8 items for instrumental orientation, i.e. the benefits associated with mastery of language, for instance, high demand of the labour market;

- 7 items for international orientation that exhibit students' attitudes to Russian language;

- 8 items were allocated to the attitude toward learning the Target language;

- 7 questions were given to motivated learning behavior comprising students' effort and persistence in their studies.

The purpose of the interview that covered seven principal themes was to gain insights into the changes occurred and their possible reasons. The main themes included also direct spoken and written contact, media contact, motivation, attitude towards language learning and students' cross-cultural orientation. To complement the results, we asked the lecturers and facilitators to give the detailed description of the tuition programme and overall characteristics of the students' profile. 


\subsection{Procedure}

Data collection took place at three particular points in time during the academic year, at approximately equal intervals. That means the first data collection was done straight after the students commenced their studies and joined the programme, then in the middle of the year before winter break, and at the end of the academic year before the exam period.

It took students about 15-20 minutes on average to complete the questionnaire depending on their level of command in the Russian language. Taking part in the research was implemented on voluntary basis. Both tutors and students were interviewed individually in a quiet room, the duration of the interview for students was 30-45 minutes and the tutor interviews lasted 45-60 minutes.

\section{Theoretical framework}

Mixed method research (MMR) [4] comprising quantitative and qualitative methods is gaining its popularity and broadening its application across a wide range of academic disciplines. This method could as well be applied to language teaching and learning and applied linguistics $[5,6]$. As an inter-discourse methodology combining quantitative and qualitative methods, MMR gives the researchers opportunity to intertwine the strengths of two methodological approaches in favor of producing more rigorous inferences in relation to the set research problems. In fact, MMR allows researchers to implement a thorough study of more complex research issues that are not possible to investigate by applying only one of these methods. In previous studies, the researchers treat MMR as a holistic methodology rather than a combination of separate methods by incorporating various epistemic perspectives in their problem conceptualization. MMR method is gaining increasing popularity and utility across a range of academic disciplines, and applied linguistics and language teaching are not exception. MMR poses its own challenges to researchers when planning and implementing their projects.

As an innovative and evolving research methodology, mixed method research imposes new challenges for potential researchers. In this article, the authors attempt to discuss MMR proposals that are of particular interest not only to researchers but also to postgraduate and doctoral students. The results could be of interest for potential students who are planning to pursue their education in the Russian Federation.

The present research is partially based on the social psychological study of inter-cultural contact with the principal subject of the investigation being the contact-attitude relation within social psychology. This subfield is called the Contact Hypothesis [7], which basically means that contacts could change behavior and attitude of individuals and groups towards one another and, vice versa, such changes would further affect contacts between groups and individuals. Contact hypothesis is seen as one of the leading theories for reducing intergroup conflict which might arise. This theory states that certain conditions such as cooperation towards a common goal, institutional support, and equal status can create a positive intergroup encounter and facilitate development of intergroup relations. However, contact hypothesis could be affected by three principal defects:

- practicality, i.e. a contact situation, which includes overcoming serious practical obstacles;

- anxiety of the participants that may lead to an unsuccessful contact or a contact with untapped potential; 
- generalization, i.e. the successful results of a contact are limited to the participant and the context of the meeting.

What are the factors required for optimal inter-group contact? The previous researches $[8,9,10,11]$ have revealed that equal status of group members, cooperation, motivation, willingness to collaborate, common goals and institutional support are necessary in order to achieve the desirable progress in studying. By means of general psychological observation, Pettigrew and Tropp (2006) figured out that familiarity led to an increase in liking due to reduction in anxiety and uncertainty [12]. It was stated that between attitudes and contact, inter-group anxiety is the main mediating variable and both direct and indirect contacts with other cultural group members influence attitudes to the out-group [13].

The findings of the previous researches closely related to study-abroad contexts [14] suggested that at the beginning of their stay the majority of students are quite optimistic and have mainly positive expectations towards the host country people, however, throughout the observed period their attitudes tend to become rather negative [15]. Overall study abroad experience, available thanks to development of academic mobility and double diploma educational programs, might be anxiety provoking and stressful for many students due to the initial cultural shock. Students might face and deal with the differences in values, cultural and moral norms, attitudes and behavior between in the new learning environment if compared to their home culture. Study abroad experience might be itself insufficient for enhancing inter-cultural sensitivity and mutual understanding, nevertheless, frequent contact with host-country groups could be vital for nurturing positive attitude change and promotes socialization and acculturation [16]. Moreover, it is of extreme importance to research students' perspectives of intercultural contacts by means of qualitative methods such as diaries and interviews being a part of MMR.

It is generally recognized that more frequent contact experiences lead to confident language use and have an impact on language learners' personal identification. Even in the situations when direct contact with Second Language speakers is minimal, the learners are exposed to cultural products in Target Language, such as videos, books, magazines, podcasts, films, social networks, etc. These cultural products play a significant role in familiarizing learners with other community and influence their attitudes. Thus, indirect contact could be considered as one the principal variables boosting motivation towards learning.

Speaking of the study abroad context, we investigated the experience of the students of mostly Vietnamese and African origin participating in a study-abroad programme in Russia using audio and video interviews and a diary study. The results revealed that a large number of participants had to cope with threats to their self-esteem and Second Language acquisition itself that negatively affected interactions with the participants from the Target Language groups. Students who succeeded in establishing strong intercultural bonds were those able to maintain control over interaction in the Target Language and their social status. Linking motivation, attitudes and interaction is study-abroad programmes for Vietnamese and African origin students, it was suggested that positive attitudes and intrinsic motivation have made a great positive impact on interaction with native speakers. Implemented qualitative analysis has shown a complex interaction between the mentioned foreign students' perceptions, identities and their involvement with the hosts in Russia. The results prove that thanks to globalization and innovative means of electronic communication immersion becomes a matter of choice and language learning in studyabroad environment will require a more profound and strong commitment nowadays.

In our study, we attempted to assess and evaluate how students' contact experiences, goals, and attitudes towards language learning have varied at three discrete time points in academic year, in particular at the beginning, middle and the end, in the context of an international study. During one academic year, foreign students majoring in various 
engineering programs study Russian language at the Department of Russian as a Foreign Language and suppose to achieve the command of Russian sufficient to continue their professional education in the Target Language.

In our research, we split types of contacts into two categories: direct contact with Target Language speakers and indirect contact using various media products. Correspondingly, for direct contact we included both written and spoken interaction and questioned host-country members as well as international students about the language use. Finally, we attempted to evaluate learners' perceptions regarding the benefits gained from encounter experience and the importance of contact. In the course of the qualitative interviews conducted retrospectively at the end of the academic year, we asked students about positive and negative interaction experiences they had had and which factors they and their facilitators had highlighted as the most important ones in fostering efficient communication with native and non-native speakers of Russian.

\section{Study and results}

\subsection{Research questions}

In our study, we have attempted to answer the following research questions:

How do encounter experiences vary at three discrete points in time throughout a period of one academic year in a Russian international study context?

Which factors influence the language learning motivation of international students partaking in a Russian international study programme? Do type of contact experiences and their frequency have an impact on students' perception?

The first part of our research was into the general characteristics of motivation for language learning and the encounter experiences of the students participating in studyabroad programme. The implemented survey allowed us to reveal that two variables such as international and instrumental orientation showed the highest mean values, while the mean values for learning attitude and motivated behavior were around 4 on a 5 point scale (see Table 1).

Table 1. Descriptive statistics of the general characteristics.

\begin{tabular}{|c|l|c|c|c|}
\hline NN & \multicolumn{1}{|c|}{ Variable categories } & $\begin{array}{c}\text { Point 1 } \\
\text { (at the } \\
\text { beginning of } \\
\text { the 1 } \mathbf{1}^{\text {st }} \text { term) }\end{array}$ & $\begin{array}{c}\text { Point 2 } \\
\text { (in the } \\
\text { middle of the } \\
\text { year) }\end{array}$ & $\begin{array}{c}\text { Point 3 } \\
\text { (at the end of } \\
\text { the academic } \\
\text { year) }\end{array}$ \\
\hline 1. & Direct spoken contact & 2.55 & 2.78 & 2.53 \\
\hline 2. & Direct written contact & 2.84 & 2.95 & 2.83 \\
\hline 3. & Media contact & 3.12 & 3.45 & 3.32 \\
\hline 4. & $\begin{array}{l}\text { Perceived importance of } \\
\text { contact }\end{array}$ & 3.44 & 3.23 & 2.98 \\
\hline 5. & Instrumental orientation & 4.87 & 4.32 & 3.98 \\
\hline 6. & International orientation & 4.92 & 4.54 & 4.32 \\
\hline 7. & Language-learning attitude & 4.15 & 3.98 & 3.67 \\
\hline 8. & Motivated learning behavior & 4.22 & 4.11 & 3.77 \\
\hline
\end{tabular}

The implemented analysis of the descriptive statistics has shown that students of this international study programme has demonstrated language learning goals and attributed high importance to the international status of language. All the mentioned goals are instrumental in nature as students mainly anticipated that opportunity of study-abroad would help them to find a better job in the home country. 
At the same time, the quantitative data have shown that students not only have strong motivation towards language learning but also have self-efficacy beliefs, i.e. they strong believe in ability to achieve proficiency level of language for their professional studies in the sphere of engineering. These results were supported by the interview data. According to the results analysis, only five out of the ten participants demonstrated confidence they would achieve the desirable level of language command. Regardless mainly positive learning attitude, the mean values for the motivated behavior were insignificantly lower. The results have shown that most of the effort the students invest in language learning is related to exams and achieving good marks. To sum up, all the students who took part in the survey exhibited strong language learning goals which are instrumental. However, the prevalence of instrumental goals does not lead to increased effort in language learning. One of the facilitators described it, "The majority of the students still have the school attitude and many of them have never attempted an independent study".

What possible explanations could be given to such findings? Firstly, students with different ethnical background might have the potentially variable cultural notions of responsibility for learning. Secondly, living in the era of developing technology, most of interview participants provided detailed accounts of how new ways of entertainment and communication enabled them to stay in touch with their home country, thus, reducing the effort put into the Target Language learning.

\subsection{The characteristics of the contact experiences of students in an international study programme}

The experimental data obtained by the questionnaire revealed that the majority of participants consider the contact with host-country members and other speakers of Russian important as through social interaction they get new knowledge about the language. At the same time, the mean values of direct, indirect and media contact variables were fixed only slightly above the middle point of scale due to the lack of frequent contact experiences. Both the quantitative and qualitative data have proven that contact with native speakers of Russian language was rather infrequent for the majority of students, partially, due to the numerous numbers of Vietnamese and French speaking members in the international students' community. The exceptions were Indian participants who managed to build up a social network consisting of native speakers. Among the reasons why students did not initiate contact with native speakers - host country members - were mentioned the lack of the following conditions: common goals, collaboration, institutional support, equal status, sufficiently high communicative ability [17]. Quite often foreign students felt left out in conversation with native speakers, neglected and disregarded. Institutional support was provided by means of extracurricular activities, however, the efforts were not sufficient apparently to encourage frequent encounters between foreign students and host country members and the necessary conditions for successful contact opportunities were not met. Five out of ten interviewees mentioned that they did not possess a sufficient level of Russian language competence to communicate with host country members, in particular with their roommates in university student residence or dormitory. These factors lead to high levels of anxiety and apprehension accompanying communication process. Students experienced fear of making mistakes, being misunderstood or not understood at all. For many students, especially the Chinese, negative communication encounters significantly increased their apprehension.

Four participants informed us they were laughed at due to their language mistakes and experienced serious communication breakdowns. Behavior of interlocutors explicitly or implicitly conveys negative attitudes and creates such feeling among the learners that their efforts in establishing contact have failed. In the result, they feel disregarded and 
disappointed. Nevertheless, the majority of the students admitted that they felt less apprehensive while speaking with international fellow students and did not experience similar negative incidents as those with native speakers.

Thus, the importance of bonding with the students of own language group should not be undermined. At the same time, when students do not have their mother tongue speakers around to rely on emotional support, e.g. a Bulgarian student, they start seeking contacts with representative of other cultures similar to their own cultures.

The quantitative data analysis also has shown the differences in direct contact experiences among representatives of various linguistic backgrounds. The results have proven that according to Schumann's (1986) Acculturation Hypothesis when the Target Language speaking community is large and the group is cohesive, the participants of Second Language will be less inclined to communicate in the Target Language with host country students and teachers. According to the Acculturation Hypothesis, some learners are progressing rapidly when acquiring a second language, while others are making a little progress in the same period, provided the same language instruction and initial abilities. As Schumann suggested such a discrepancies arise due to characteristics of the psychological and social distances between learners and the Target language. Eight characteristics of social distance could be distinguished (table 2) [18].

Table 2. Characteristics of social distance.

\begin{tabular}{|l|l|}
\hline \multicolumn{1}{|c|}{ Characteristic } & \multicolumn{1}{c|}{ Description } \\
\hline $\begin{array}{l}\text { Social Dominance } \\
\text { Patterns }\end{array}$ & $\begin{array}{l}\text { When the native language learners view their group as superior in } \\
\text { terms of culture, politics, technology, or economics, they are not } \\
\text { willing to learn the second language. }\end{array}$ \\
\hline $\begin{array}{l}\text { Integration } \\
\text { strategies }\end{array}$ & $\begin{array}{l}\text { There are three types of learners: assimilative, preservative, and } \\
\text { adaptive. Assimilative learners give up their native language values and } \\
\text { lifestyles, whereas preservative ones keep them. Adaptive learners } \\
\text { become bicultural and are able to switch depending on the group. }\end{array}$ \\
\hline Enclosure & $\begin{array}{l}\text { Enclosure is low when groups share social facilities. This facilitates } \\
\text { language learning. }\end{array}$ \\
\hline $\begin{array}{l}\text { Intended Length of } \\
\text { Residency }\end{array}$ & $\begin{array}{l}\text { The length of planned stay in the country and the permanency of } \\
\text { residency greatly affect motivation towards learning a new language } \\
\text { (the average stay in Russia of the participants of this research accounts } \\
\text { for 5 years). }\end{array}$ \\
\hline Cohesiveness & $\begin{array}{l}\text { Strong intragroup contact within the community of the native language } \\
\text { speakers with few outside contacts affects second language learning. }\end{array}$ \\
\hline Size & $\begin{array}{l}\text { Second language acquisition is affected by the size of the native } \\
\text { language community. }\end{array}$ \\
\hline $\begin{array}{l}\text { Cultural } \\
\text { congruence }\end{array}$ & $\begin{array}{l}\text { Second language learning is affected by the similarity and harmony } \\
\text { between cultures. }\end{array}$ \\
\hline Attitudes & $\begin{array}{l}\text { The feelings of the reference groups toward each other may also } \\
\text { influence second language learning. }\end{array}$ \\
\hline
\end{tabular}

Speaking of characteristics of psychological distance arising between second language learners, four characteristics could be marked out (table 3).

Table 3. Characteristics of psychological distance.

\begin{tabular}{|l|l|}
\hline \multicolumn{1}{|c|}{ Characteristic } & \multicolumn{1}{c|}{ Description } \\
\hline Language shock & $\begin{array}{l}\text { If the learners feel silly about trying to learn the language, they are less } \\
\text { likely to learn. }\end{array}$ \\
\hline Culture shock & $\begin{array}{l}\text { Being disoriented or anxious in a foreign culture equates to less likely to } \\
\text { learn the second language. }\end{array}$ \\
\hline Motivation & $\begin{array}{l}\text { Level of motivation has an impact on acquisition of the second } \\
\text { language. }\end{array}$ \\
\hline
\end{tabular}


\begin{tabular}{|l|l|}
\hline Ego-permeability & $\begin{array}{l}\text { If second language learners view their first language as fixed and rigid at } \\
\text { the certain extent, this affects their learning of the second language. }\end{array}$
\end{tabular}

Indirect contact through numerous available media, such as TV, the Internet, radio, magazines, books, podcasts, do not tend to be frequent similar to direct spoken contact. Some students watched popular TV shows in Russian, but rather for entertaining purposes than for educational ones [19]. Very few reading activities were reported; the only exception included some compulsory reading for academic purposes and some electronic texts on the Internet. In recent years, the Internet has become an important and easily accessible communication medium. It creates such an environment for users where they feel more protected and exercise more control over the process of communication. The unique qualities of the Internet enable users to create a positive contact between rival groups.

Social networking sites in Russian were also used rarely; the same situation was applied to writing emails in Russian. To sum up, both qualitative and quantitative data related to direct spoken communication emphasize the impact of inter-group anxiety and on students' willingness to engage in intercultural communication [20]. The results of this investigation demonstrate that international students from study-abroad programs mainly socialize within their own ethnical group due to high communication anxiety and perceived threats to their self-esteem. However, these findings do not exclude friendships between students from different ethnic background as they facilitate students' social and cultural blending into the host society.

\section{Discussion}

In this section, there will discussed motivational and contact variables throughout one academic year. During one academic year we observed a remarkable reduction in the values of all the variables apart from direct written contact. The results exhibited in the Table 1 show that the mean values of contact and motivational variables demonstrated a sharp decline between Point 2 and Point 3 of the program, with the exception of direct spoken contact between Point 1 and Point 3. The impact of time on contact and motivational variables was substantial, apart from direct spoken contact aspect demonstrating the medium range results.

Overall, considering the changes in the questionnaire data (Table 1), we can make the conclusion that no significant changes took place in the first semester between the Point 1 and the Point 2 with the exception of direct media and written contact while attitude and motivation remained rather stable. However, even three months after arrival spoken contact experiences of students have not improved dramatically due to high level of communication anxiety and occurring negative experiences of interactions with native speakers. As the result of this, students tried to avoid face-to-face encounters with host-country members and bonded even strongly with their first language group in order to protect their selfesteem. Some Chinese students, for example, even adopted the avoidance strategy for communication with native speakers. We can draw a conclusion that the experiences when foreign students felt valued members of the host community were rather rare.

The data collected by means of the interviews have shown the important role of events for similar arguments regarding the willingness to communicate. The data illustrated that the majority of our participants described remarkable events, such as students' conferences, workshops, Interclub meetings, intercultural concerts, had changed their attitude and willingness to communicate with native speakers and to evolve the further communication. It is also apparent that negative effect on the international students could have been avoided throughout the most of the events if their counterparts had shown more understanding of 
the cross-cultural difficulties arising due to the clash of cultures and had tried to support and encourage students instead of opting out of the conversation [21].

Nevertheless, direct written and media contact turned out to be more frequent between Point 1 and Point 2 . This could be explained by the instructional tasks given to the students by their tutors throughout the nine months course. During the second term of the programme, students were asked to keep a reflective diary of the watched media sources as well as the magazines articles and journals papers they read. Thus, in a study-abroad context, instructional tasks and institutional support play a crucial role in the attempt to engage students in media and written contact in the Target Language.

As we can see from the obtained results, there was a considerable fall in the contact frequency by the year end. According to the curriculum, at the end of a study-abroad programme, students take exams in both Russian language and some content area disciplines. As mentioned by the interviewees, the last period of the second term is commonly dedicated to preparing for these exams; therefore students normally have less time to engage in face-to-face contact with each other and with native language speakers.

As far as the motivational variables are concerned, their mean values have also decreased at the Point 3 of the period. This could be explained by the fact that the students considered their official language learning period to be over and the language would cease to be the object of study. Instead the language from then on would become a tool for acquiring knowledge in their further professional studies. Another reason for the drop in motivation might be that in this particular period of time the interviewees were focused on the exams content and therefore paid less attention to the language skills improvement.

\section{Conclusions}

In the present research, the authors attempted to investigate direct and indirect crosscultural contact as well as motivated behavior and language attitude in a study-abroad context in the Russian Federation. In the study, the authors applied the mixed method combining quantitative and qualitative research methodologies in order to demonstrate contact, behavioral and motivational variable throughout one academic year of the foundation programme. The obtained results proved that written and media use contacts had become more frequent during the year whereas the direct spoken contacts had exhibited the opposite tendency.

Basing our conclusions on the quantitative and qualitative data, we suggested three principal groups of factors determining the type and the amount of students' cross-cultural experience. First of all, one should mention the socio-environmental factors that comprise the size of the Source Language speaking community in the host country and the conflict arising from students' attitudes, expectations and cultural beliefs and those of the host country. In this aspect, institutional support plays crucial role in establishing direct and indirect contact with the Target Language, also by means of organizing the remarkable and memorable events.

The second factor to be mentioned includes internal variables, e.g. personal attitude towards language learning, self-confidence, intrinsic motivation, self-esteem, communication apprehension and others. All these components predetermine the willingness to communicate and the contact frequency and quality.

Finally, the third group of factors relates to the importance of significant events for successful interaction with native speakers in a study abroad context.

The experiential history of the participants complements and dynamically interacts with the social and institutional context and learners' personality traits [22, 23].

To sum up, several conclusions could be drawn on the base of the implemented research. First of all, the study emphasizes the importance of preparing students for their 
study abroad programme before their arrival to the host country both in developing communication skills and strategies and their linguistic ability [24]. Upon arrival, a necessary precondition for students is providing institutional support enabling them to adjust to the new cultural and social environment and to establish contact with native speakers. As the analysis of the results illustrate, self-confidence of foreign students can suffer dramatically from the negative encounter experiences that could have been avoided or fully eliminated if the hosts had been better prepared for social interaction and communication. Thus, institutional support is to help host country members to understand the attitudes, expectation, feeling and possible forms of the international students' behavior. All these measures would help encourage contact opportunities and reduce inter-group anxiety among foreign students.

\section{Acknowledgements}

This paper has been supported by the RUDN University Strategic Academic Leadership Program.

\section{References}

1. R.D. Lewis, Training, Language and Culture 3(3), 8-20 (2019) doi: 10.29366/2019tlc.3.3.1

2. I. Ristic, Ya.B. Zhang, N. Liu, Journal of Intercultural Communication Research 48(6), 589-607 (2019) https://doi.org/ 10.1080/17475759.2019.1695651

3. E.N., Malyuga, A., Krouglov, B. Tomalin, XLinguae 11(2), 566-582 (2018) DOI: 10.18355/XL.2018.11.02.46

4. M. Riazi, C. Candlin, Language Teaching 47(2), 135-173 (2014) https://doi.org/10.1017/S0261444813000505

5. E. Cardenas-Lopez, Teaching English Learners in Middle Grades: A Mixed Method Study of the Dispositions, Priorities, and Instructional Practices of Urban Bilingual, ESL, and Content Teachers, Dissertations (2015) https://digitalcommons.nl.edu/diss/112

6. A.V., Radyuk, V.Yu. Pankova, Training, Language and Culture 1(3), 30-38 (2017) Doi: $10.29366 / 2017$ tlc. 1.3 .2

7. S. McKeown, J. Dixon, Social and Personality Psychology Compass 11(1), e12295 (2017) https://doi.org/ 10.1111/spc3.12295

8. T.F. Pettigrew, L.R. Tropp, On the Nature of Prejudice: Fifty Years after Allport, 262277 (2008) https://doi.org/ 10.1002/9780470773963.ch16

9. E.L. Paluk, S.A. Green, D.P. Green, The contact hypothesis re-evaluated (Cambridge University Press, 2018) doi:10.1017/bpp.2018.25

10. E., Malyuga, B. Tomalin, J. of Language and Literature 5(4), 172-180 (2014) doi: 10.7813/j11.2014/5-4/38

11. S. Zhou, E. Page-Gould, A. Aron, A. Moyer, M. Hewstone, Pers. Soc. Psychol. Rev. 23(2), 132-160 (2019) https://doi.org/10.1177/1088868318762647

12. T.F. Pettigrew, L.R. Tropp, European Journal of Social Psychology 38(6), 922-934 (2008) https://doi.org/10.1002/ejsp.504

13. P. Macintyre, R. Gardner, Language Learning 41(1), 85-117(1991) https://doi.org/10.1111/j.1467-1770.1991.tb00677.x 
14. P. Macintyre, R. Clement, Z. Dörniei, K.A. Noeis, Modern Language Journal 82(4), 545-562 (1998) https://doi.org/ 10.1111/j.1540-4781.1998.tb05543.x

15. W. Cajkler, R. Addelman, The Practice of Foreign Language Teaching (London and NY, Routledge, 2000)

16. Chapelle S. Sauro, Handbook of technology and second language teaching and learning (Hoboken, NJ, Wiley Blackwell, 2017).

17. J. Waterworth, K. Hoshi, Human-Experiential Design of Presence in Everyday Blended Reality (2016) https://doi.org/10.1007/978-3-319-30334-5

18. A. Teemant, S. Pinnegar, Understanding Language Acquisition (Provo, UT, Brigham Young University, 2007)

19. M.U. Çelik, S. Casimoğlu, Amazonia Investiga 7(16), 254-260 (2018) https://www.amazoniainvestiga.info/index.php/amazonia/article/view/401

20. A. Awwad, J. of Asia TEFL 16(2), 468-484 (2019) https://doi.org/ 10.18823/asiatefl.2019.16.2.2.468

21. S. Avtonomova, L. Kutyrkina, D. Fedyunin, V. Bezpalov, S. Lochan, Amazonia Investiga 8(19), 173-178 https://www.amazoniainvestiga.info/index.php/amazonia/article/view/217

22. C.T. Williams-McBean, Qualitative Report 24(5), 1055-1064 (2019)

23. V. V. Vetrinskaya, T. A. Dmitrenko, Training, Language and Culture 1(2), 22-39 (2017) Doi: 10.29366/2017tlc.1.2.2

24. A.V. Pellegrino, Language in Society 36(1), 140-141 (2007) https://doi.org/10.1017/S0047404507250067

25. L.R. Tropp, J. of Personality and Social Psychology, 90(5), 751-83 (2006). https://doi.org/10.1037/0022-3514.90.5.751

26. K. Ramage, Language Learning 40(2), 189-219 (2006)

27. B.L. Reynold, Program for Promoting Teaching Excellence of Universities 10(4), 561590 (2019) https://doi.org/10.1515/applirev-2017-0046

28. W. Zhang, D. Su, M. Liu, Journal of Language Teaching and Research 4(1), 58-66 (2013) 